\title{
Is audit and feedback associated with increased hospital adherence to standards for communication during patient care transitions?
}

\author{
Rosa R Baier ${ }^{1,2}$, Lorraine A. Limpahan ${ }^{3}$, Kristen Butterfield ${ }^{1}$, Maureen Marsella ${ }^{1}$, Stefan \\ Gravenstein $^{1,4}$, Rebekah L. Gardner ${ }^{1,4}$
}

1. Healthcentric Advisors, Providence, RI, United States. 2. Brown University School of Public Health, Providence, RI, United States. 3. Brown University, Providence, RI, United States. 4. Warren Alpert Medical School of Brown University, Providence, RI, United States.

Correspondence: Rosa R Baier. Address: 235 Promenade Street, Suite 500, Box 18, Providence, RI 02908, United States. E-mail: rbaier@healthcentricadvisors.org

Received: J uly 9, 2014

DOI : $10.5430 /$ jha.v3n6p1
Accepted: August 4, 2014

URL: http://dx.doi.org/10.5430/jha.v3n6p1

\begin{abstract}
Guidelines to enhance communication during patient care transitions between healthcare settings have the potential to improve patient outcomes and satisfaction, as well as to decrease overall costs. In 2009, Healthcentric Advisors, the Medicare Quality Improvement Organization (QIO) for New England, collaborated with Rhode Island providers and stakeholders to develop communitywide standards for hospitals, the Safe Transitions Best Practice Measures for Hospitals and then implemented a hospital quality improvement intervention. As part of this intervention, 10 of the state's 11 acute-care hospitals collected quarterly data and Healthcentric Advisors provided audit and feedback reports showing each facility's progress and the state's average performance. Using hospital-reported data on four best practice measures and Medicare claims data for Q2 2011-Q1 2013, we performed descriptive analyses of (1) inpatient-to-outpatient communication for all patients at the 10 participating hospitals, as measured by four best practice measures, and (2) state-wide all-cause, 30-day readmission rates per 1,000 fee-for-service (FFS) beneficiaries. Aggregate performance for the four best practice process measures increased by $5.5 \%$ to $217.6 \%$ for all patients who met eligibility criteria $(p \leq .001$ for each measure) and the readmission rate decreased by $18.4 \%$ from 14.12 to 11.52 per 1,000 eligible FFS Medicare beneficiaries $(p \leq .001)$. These findings suggest that communitywide standards, such as the Safe Transitions Best Practice Measures for Hospitals, and audit and feedback interventions can successfully improve hospitals' communication during patient care transitions between healthcare settings.
\end{abstract}

\section{Key words}

Care transitions, Readmission, Communication, Quality improvement, Hospital discharge

\section{I ntroduction}

National organizations and consensus statements recognize the importance of cross-setting communication and cite it as a top priority for improvement ${ }^{[1-3]}$. Guidelines to enhance communication during patient care transitions between healthcare settings have the potential to improve health outcomes and patient satisfaction, as well as to decrease overall 
healthcare costs ${ }^{[4-6]}$. During care transitions, patients' clinicians, including hospital-based clinicians and communitybased primary care providers (PCPs), are responsible for sharing clinical information across settings and communicating directly, if necessary, to address time-sensitive questions and to transfer accountability for patients' care ${ }^{[1,2,7]}$.

Despite the importance of cross-setting communication, the complex, fragmented nature of the U.S. healthcare system leads to significant variability in the frequency, quality and effectiveness of cross-setting communication ${ }^{[8-10]}$. It is increasingly rare for PCPs to follow their patients in the hospital, so hospital physicians must transfer responsibility for patient care to PCPs at hospital discharge ${ }^{[11]}$. Multiple barriers impede timely, complete communication during inpatientto-outpatient transitions and contribute to readmission or other adverse events ${ }^{[11]}$; barriers include lack of uniform standards for information transfer ${ }^{[3]}$. Although patients and caregivers can communicate information among providers and between care settings, their variable understanding of the care episode and discharge instructions may prevent them from completely filling the communication gap ${ }^{[12]}$.

In 2008, Healthcentric Advisors, the Medicare Quality Improvement Organization (QIO) for New England, received a competitively-awarded Centers for Medicare \& Medicaid Services (CMS) contract to reduce hospital readmission rates in Rhode Island and began working with providers in multiple settings, including hospitals, to form multi-disciplinary teams to improve care transitions. At that time, we identified opportunities to improve the form, content and timing of information transfer from the hospital to the community physician office, prompting us to collaborate with providers and stakeholders to develop communitywide standards for multiple settings ${ }^{[13,14]}$, including hospitals ${ }^{[15]}$, in 2009 and 2010. The Safe Transitions Best Practice Measures for Hospitals ${ }^{[16]}$ establish measurable expectations for hospital-to-PCP communication and have served as the basis for an audit and feedback intervention since 2011. The Rhode Island Office of the Health Insurance Commissioner began requiring commercial health plans to include these measures in hospital contracts in $2012^{[17]}$.

\section{Methods}

\subsection{I ntervention}

After developing the Safe Transitions Best Practice Measures for Hospitals, we implemented an audit and feedback intervention with Rhode Island's 11 acute-care hospitals. Beginning in 2011, three years after launching our statewide Safe Transitions project, we asked hospitals' care transitions teams to volunteer to collect quarterly data for the nine best practice measures and to submit these data to us quarterly via email. We provided reports back to each hospital's care transitions team, showing their facility's progress and the state's average performance. Our hospital program coordinator, a nurse, then collaborated with each hospital's care transitions team, providing targeted technical assistance to help staff implement quality improvement methods designed to improve their performance. The 10 participating hospitals were allowed to freely choose when to begin reporting data for each best practice and encouraged to begin collecting data from a single unit or floor and then expand data collection hospital-wide over time.

\subsection{Data sources}

We used (1) self-reported hospital process measure data all patients and (2) fee-for-service (FFS) Medicare claims data provided quarterly to Healthcentric Advisors by CMS. Both data sources reflected the time period from Q2 (April-June) 2011 through Q2 (April-June) 2013.

\subsection{Measures}

We analyzed four process measures and one outcome measure (see the table for detailed descriptions of the measures, including eligibility criteria and operational definitions of the process measures). The process measures are the four Safe 
Transitions Best Practice Measures that center on inpatient-to-outpatient communication (five additional measures focus on patient activation and medication reconciliation). The measures are the percent of all patients with:

- Notification of hospitalization sent to PCPs at beginning of hospital visit;

- Hospital clinicians' contact information provided to receiving clinicians upon discharge;

- Follow-up appointment scheduled within one business day of discharge; and

- Hospital summary clinical information sent to PCPs at discharge.

The outcome measure was all-cause, 30-day hospital readmission rates per 1,000 eligible FFS Medicare beneficiaries. The use of a population-based measure allows us to account for longitudinal decreases in both admissions and readmissions.

Table. Rhode Island Hospitals' performance on safe transitions best practices measures and 30-day, all-cause readmission rates, Q2 2011-Q2 2013

\begin{tabular}{|c|c|c|c|c|c|c|}
\hline \multirow{2}{*}{ Measures } & \multirow{2}{*}{ Description } & \multicolumn{4}{|c|}{ Aggregate Hospital Performance } & \multirow{2}{*}{$p$-value } \\
\hline & & \multicolumn{2}{|c|}{ Q2 2011, n (\%) } & \multicolumn{2}{|c|}{ Q2 2013, n (\%) } & \\
\hline \multicolumn{7}{|c|}{ Process Measures (Intervention, $\mathbf{N}=10$ Hospitals) } \\
\hline $\begin{array}{l}\text { Notification of } \\
\text { hospitalization sent to } \\
\text { PCPs at beginning of } \\
\text { hospital visit }\end{array}$ & $\begin{array}{l}\text { Among all discharged patients, the percent with } \\
\text { documented notification to the PCP office within } \\
24 \text { hours of the initial order for outpatient } \\
\text { observation or inpatient admission }\end{array}$ & 6,089 & $(82.3 \%)$ & 40,735 & $(86.8 \%)$ & $<.001$ \\
\hline $\begin{array}{l}\text { Hospital clinicians' } \\
\text { contact information } \\
\text { provided to receiving } \\
\text { clinicians upon discharge }\end{array}$ & $\begin{array}{l}\text { Among patients whose Rhode Island inter-agency } \\
\text { transfer form was audited, the percent whose form } \\
\text { includes contact information for the clinician who } \\
\text { cared for the patient or has access to the patient's } \\
\text { medical record }\end{array}$ & 806 & $(66.3 \%)$ & 10,198 & $(97.4 \%)$ & $<.001$ \\
\hline $\begin{array}{l}\text { Follow-up appointment } \\
\text { scheduled within one } \\
\text { business day of discharge }\end{array}$ & $\begin{array}{l}\text { Among all discharged patients, the percent with } \\
\text { documentation that (1) an outpatient PCP or } \\
\text { specialist appointment was scheduled within } 14 \\
\text { days, and (2) information was provided to the } \\
\text { patient or caregiver }\end{array}$ & 1,182 & $(55.0 \%)$ & 16,501 & $(90.2 \%)$ & $<.001$ \\
\hline $\begin{array}{l}\text { Hospital summary } \\
\text { clinical information sent } \\
\text { to PCPs at discharge }\end{array}$ & $\begin{array}{l}\text { Among all discharged patients, the percent with } \\
\text { documentation that a Rhode Island inter-agency } \\
\text { transfer form or draft Discharge Summary was } \\
\text { sent to the PCP office within } 24 \text { hours of } \\
\text { discharge }\end{array}$ & 643 & $(29.5 \%)$ & 14,127 & $(93.7 \%)$ & $<.001$ \\
\hline \multicolumn{7}{|c|}{ Outcome Measure (Statewide, $\mathrm{N}=11$ Hospitals) } \\
\hline $\begin{array}{l}\text { 30-day all-cause hospital } \\
\text { readmission }\end{array}$ & $\begin{array}{l}\text { All-cause hospital readmissions within } 30 \text { days } \\
\text { of hospital discharge per } 1,000 \text { eligible FFS } \\
\text { Medicare Beneficiaries }\end{array}$ & 1,705 & $(14.12)$ & 1,454 & (11.52) & $<.001$ \\
\hline
\end{tabular}

\subsection{Data analysis}

We calculated the percent of patients in the acute-care hospitals who met criteria for each of the four best practice process measures. Ten of Rhode Island's 11 acute-care hospitals provided best practice process measure data; the 11th hospital elected not to participate in this component of the statewide Safe Transitions project. We conducted all best practice analyses in aggregate (for all 10 hospitals, not individual facilities), since we were not powered to evaluate change between baseline and re-measurement at the hospital level. We conducted a test for proportions to determine if there was a significant difference between best practice performance at baseline and re-measurement. 
We calculated quarterly 30-day all-cause readmissions per 1,000 FFS Medicare beneficiaries, by dividing the number of hospital readmissions by the total number of eligible Medicare beneficiaries and multiplying the resulting figure by 1,000 . These analyses were statewide and therefore included all 11 acute-care hospitals in Rhode Island, including the one hospital that elected not to participate in the intervention. We conducted a test for proportions to determine if there was a significant difference between readmission rates at baseline and re-measurement.

We conducted the best practice analyses using Microsoft Excel (Redmond, WA) and the claims analyses using SAS v.9.2 (Cary, NC). We hypothesized that we would see increased inpatient-to-outpatient communication (as measured by the best practice process measures) and decreased hospital readmission per 1,000 beneficiaries.

\section{Results}

Ten of Rhode Island's 11 acute-care hospitals (90.9\%) provided best practice data, received audit and feedback reports and implemented targeted interventions to improve best practice performance. The 10 participating hospitals were allowed to freely choose when to begin reporting data for each best practice and encouraged to begin collecting data from a single unit or floor and then expand data collection hospital-wide over time. As a result, the number of measures that each hospital employed varied between Q2 2011 and Q2 2013, as did the number of patients reflected in those measures.

From Q2 2011 to Q2 2013, hospitals' aggregate performance for each of the four best practice process measures increased by $5.5 \%$ to $217.6 \%$ ( $p \leq .001$ for each measure) (see the table and figure). The increase was greatest for "hospital summary clinical information sent to primary care providers at discharge", which increased $217.6 \%$ from $29.5 \%$ to $93.7 \%(p \leq .001)$ and least for "notification of hospitalization sent to PCPs at beginning of hospital visit", which increased 5.5\% from $82.3 \%$ to $86.8 \%$ ( $p \leq .001$ ). "Follow-up appointment scheduled prior to discharge" increased $64.0 \%$ from $55.0 \%$ to $90.2 \%(p$ $\leq .001)$ and "hospital clinicians' contact information provided to receiving clinicians upon discharge" increased $46.9 \%$ from $66.3 \%$ to $97.4 \%(p \leq .001)$.

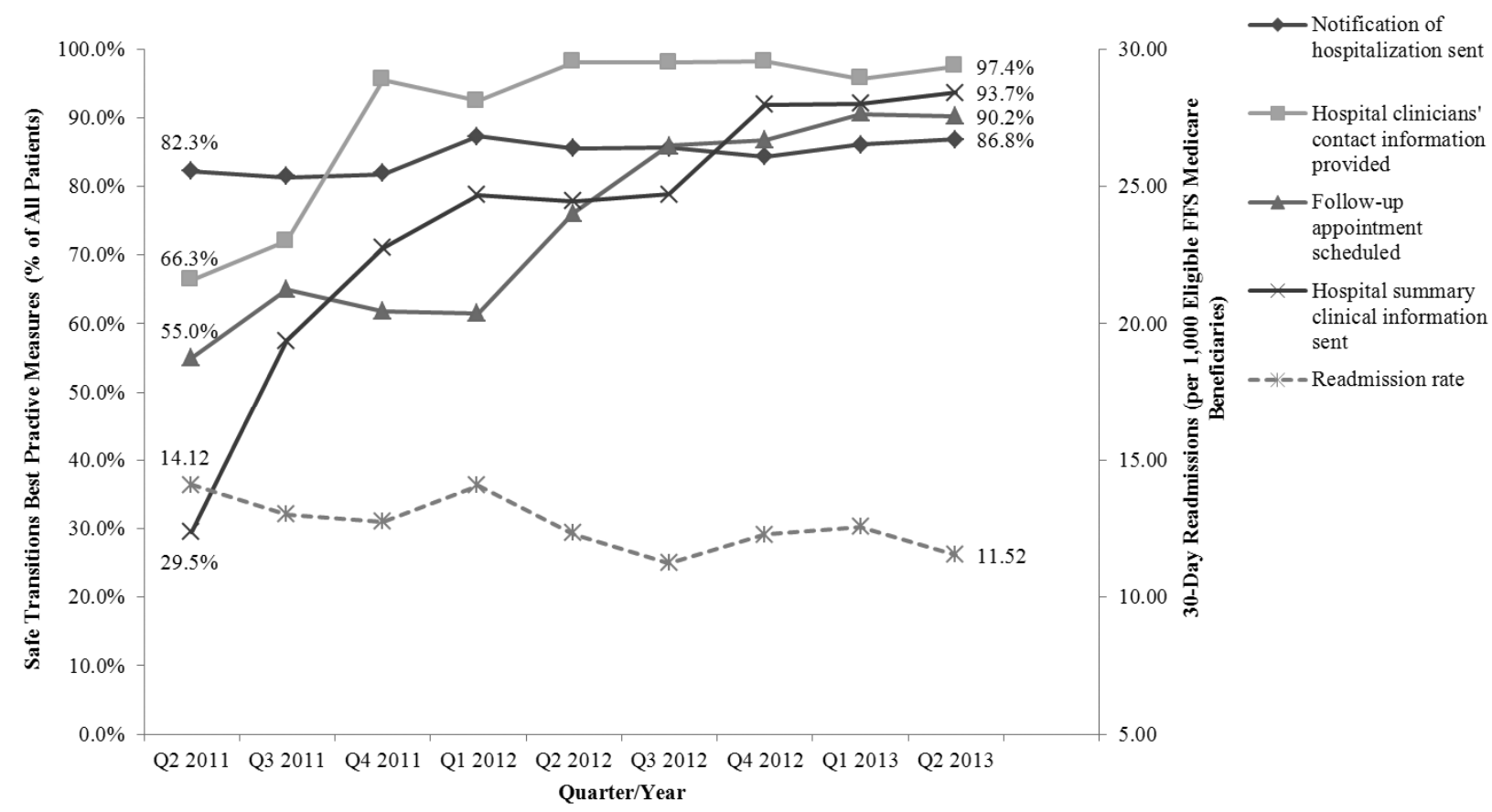

Figure. Rhode Island Hospitals' performance on safe transitions best practices measures and 30-day, all-cause readmission rates, Q2 2011-Q2 2013 
From Q2 2011 to Q2 2013, Rhode Island's statewide all-cause, 30-day hospital readmission decreased by $18.4 \%$ from 14.12 per 1,000 FFS Medicare beneficiaries to 11.52 per 1,000 FFS Medicare beneficiaries $(p \leq .001)$ (see the table and figure).

\section{Discussion}

Our findings suggest that a quality improvement intervention using audit and feedback can successfully increase hospitals' adherence to standards for communication during patient care transitions between healthcare settings. The results show that, overall, 10 Rhode Island hospitals' communication with PCPs improved from baseline to re-measurement of the audit and feedback intervention. At the same time, Rhode Island's statewide 30-day, all-cause readmission rate for FFS Medicare patients decreased.

Although the process measure data are self-reported, our findings are supported by the results of a recent survey administered by the Rhode Island Executive Office of Health and Human Services. Among a convenience sample of 63 PCPs surveyed electronically in November 2013, nearly eight in 10 (79.3\%) agreed that written communication from hospitals had improved in the past three years, while fewer than half (43.9\%) agreed that oral communication had improved in that timeframe (unpublished data). Because the best practices focus on hospitals' written (vs. oral) communication, the fact that PCPs agreed more strongly that written communication had improved appears to support our belief that the increase in adherence to the process measures reflects true improvement in communication.

While the best practice concepts may seem intuitive and may, in fact, be supported by Joint Commission or other requirements, we developed the measures based on community feedback that these processes are not being consistently used by every clinician, in every hospital. When developing the best practices, we drew on consensus statements, the medical literature, and hospital-based interventions ${ }^{[15]}$. Several hospital interventions addressing patient- and systemslevel factors have improved patient transitions and readmissions. For example, Project RED (Re-Engineered Discharge) decreased 30-day emergency department visits and readmissions by about 30\% among patients randomized to receive an intervention involving 12 discrete, mutually reinforcing components ${ }^{[6]}$. The Care Transitions Intervention (CTI) also decreased 30-day hospital readmission by about 30\% among patients who were randomized to receive health coaching for 30 days following hospital discharge ${ }^{[4]}$ and in another quality improvement intervention ${ }^{[18]}$. The CTI focuses on empowering high-risk patients to better manage their illnesses through a home visit and telephone calls by trained transitions coaches ${ }^{[4]}$.

Our findings should be interpreted in the context of other local initiatives and should not be attributed wholly to our intervention. For example, the Rhode Island Office of the Health Insurance Commissioner began requiring commercial health plans to include the best practices in hospital contracting in $2012^{[17]}$, during the time period reflected in this analysis. Although hospitals' contracts are confidential, are renegotiated at different time periods, and may vary from hospital to hospital, we believe that all 10 participating acute-care hospitals now have contracts that specifically require them to measure the best practice processes. There are incentives or payment penalties associated with performance on some of these measures. The inclusion of the best practices in contracting supports our team's ongoing efforts to align payment and policies with these community-endorsed processes. These efforts complicate attribution, but support our overall goal: to change the culture of care transitions care delivery and to catalyze sustainable systems change throughout Rhode Island.

Our findings have several additional limitations, largely due to the fact that this is a quality improvement intervention implemented with volunteer hospitals and in real-world conditions. First, the analysis is descriptive and cannot link improved hospital communication with a reduced hospital readmission rate. Second, the 10 participating hospitals were allowed to freely choose when to begin reporting data for each best practice and encouraged to begin collecting data for a single unit or floor and then expand data collection. As a result, the number of measures that each hospital employed varied throughout the two-year period, as did the number of patients reflected in the measures data. This impacts our 
interpretation of the comparison between baseline and re-measurement performance, although our findings are supported by the Rhode Island Executive Office of Health and Human Services survey. Third, this analysis focuses on inpatientto-outpatient communication and does not evaluate progress toward improving any of the other locally identified root causes of poor transitions or high readmission rates, either in hospitals or other healthcare settings. Additional research is necessary to link best practice process measure performance (individually or as a bundle) with improvements in outpatient PCPs' perceptions of hospital communication and to examine the association between the improvement in the best practices and reduced 30-day, all-cause hospital readmission rates.

These findings suggest that implementation of the audit and feedback intervention is associated with an increase in Rhode Island acute-care hospitals' adherence to the best practice process measures. Communitywide standards, such as the Safe Transitions Best Practice Measures for Hospitals, have potential to guide and direct providers' communication practices. They provide a framework for hospital leaders to expand their collaboration with community partners in the context of emerging payment models, such as Accountable Care Organizations and bundled payments. They also propose a standard that can catalyze introspection and debate about our culture of care, as well as about how to improve communication and accountability across the care continuum.

\section{Disclaimer}

This material was prepared by Healthcentric Advisors, the Medicare Quality Improvement Organization for New England, under contract with the Centers for Medicare \& Medicaid Services (CMS), an agency of the U.S. Department of Health and Human Services. The analyses on which this report is based were performed under Contracts HHSM-500-2008-RI and HHSM-500-2011-RI11SOC, entitled "Utilization and Quality Control Peer Review for the State of Rhode Island". The contents presented do not necessarily reflect CMS policy.

\section{Acknowledgements}

The authors thank the providers and stakeholders who participated in the development of the Safe Transitions Best Practice Measures for Hospitals, including the Hospital Quality Directors and the members of the Safe Transitions Leadership Advisory Board; the Rhode Island Office of the Health Insurance Commissioner, for requiring commercial health plans to incorporate the Safe Transitions Best Practice Measures into hospital contracting; and, most importantly, the hospital staff participating in the audit and feedback intervention who have collected and submitted best practice process measure data since 2011 .

\section{References}

[1] Coleman EA, Boult C. The American Geriatrics Society Health Care Systems Committee. Improving the quality of transitional care for persons with complex care needs. J Am Geriatr Soc. 2003; 51(4): 556-557. PMid: 12657079. http://dx.doi.org/10.1046/j.1532-5415.2003.51186.x

[2] Snow V, Beck D, Budnitz T, et al. Transitions of care consensus policy statement: American College of Physicians, Society of General Internal Medicine, Society of Hospital Medicine, American Geriatrics Society, American College Of Emergency Physicians, and Society for Academic Emergency Medicine. Journal of Hospital Medicine. 2009 Jul; 4(6): 364-70. PMid: 19479781. http://dx.doi.org/10.1002/jhm.510

[3] Jaquis W, Kaplan J, Carpenter C, et al. Transitions of Care Task Force Report. 2012 Sep; 1-25. Available from: http://www.acep.org/transitionsofcare/

[4] Coleman EA, Parry C, Chalmers S, Min SJ. The care transitions intervention: results of a randomized controlled trial. Arch Intern Med. 2006; 166(17): 1822-8. PMid: 17000937. http://dx.doi.org/10.1001/archinte.166.17.1822

[5] Naylor MD, Brooten DA, Campbell RI, Maislin G, McCauley KM, Schwartz JS. Transitional care of older adults hospitalized with heart failure: a randomized, controlled trial. J Am Geriatr Soc. 2004; 52(5): 675-84. PMid: 15086645. http://dx.doi.org/10.1111/j.1532-5415.2004.52202.x 
[6] Jack BW, Cherry VK, Anthony D, et al. A reengineered hospital discharge program to decrease rehospitalization: a randomized trial. Ann Intern Med. 2009; 150(3): 178-87. PMid: 19189907. http://dx.doi.org/10.7326/0003-4819-150-3-200902030-00007

[7] Jencks SF, Williams MV, Coleman EA. Rehospitalizations among patients in the Medicare fee-for-service program. N Engl J Med. 2009; 360(14): 1418-28. PMid: 19339721. http://dx.doi.org/10.1056/NEJMsa0803563

[8] Gillespie SM, Gleason LJ, Karuza J, Shah M. Healthcare providers' opinions on communication between nursing homes and emergency departments. J Am Med Dir Assoc. 2010; 11(3): 204-10. PMid: 20188318. http://dx.doi.org/10.1016/j.jamda.2009.09.002

[9] Carrier E, Yee T, Holzwart RA. Coordination between emergency and primary care physicians. National Institute for Health Care Reform. 2011; Research Brief No. 3. Available from: http://www.nihcr.org/ED-Coordination.html

[10] Terrell KM, Miller DK. Challenges in transitional care between nursing homes and emergency departments. J Am Med Dir Assoc. 2006; 7: 499-505. PMid: 17027627. http://dx.doi.org/10.1016/j.jamda.2006.03.004

[11] Kripalani S, Jackson AT, Schnipper JL, Coleman EA. Promoting effective transitions of care at hospital discharge: a review of key issues for hospitalists. Journal of Hospital Medicine. 2007 Sept/Oct; 2(5): 314-23. PMid: 17935242. http://dx.doi.org/10.1002/jhm.228

[12] Samuels-Kalow ME, Stack AM, Porter SC. Effective discharge communication in the emergency department. Ann Emerg Med. 2012; 60(2): 152-9. PMid: 22221840. http://dx.doi.org/10.1016/j.annemergmed.2011.10.023

[13] Limpahan LA, Baier RR, Gravenstein S, Liebmann O, Gardner RL. Reducing care fragmentation during patient transitions: Emergency department care transition best practices. Am J Emerg Med. 2013 Sep; 31(9): 1297-301. PMid: 23816191. http://dx.doi.org/10.1016/j.ajem.2013.04.017

[14] Shamji H, Baier RR, Gravenstein S, Gardner R. Reducing care fragmentation during patient transitions: best practices for urgent care centers. Jt Comm J Qual Safet. Jul 2014; 40(7): 319-324.

[15] Baier RR, Gardner R, Gravenstein S, Besdine R. Partnering to improve hospital-physician office communication through by implementing care transitions best practices. Health/Medicine RI 2011 Jun; 178-182.

[16] Healthcentric Advisors. Safe transitions best practice measures. 2009. Available from: http://www.healthcentricadvisors.org/safe-transitions-cp/bps.html. Accessed June 19, 2014

[17] Rhode Island Office of the Health Insurance Commissioner. 2012 rate review process hospital contracting conditions. 2012. Available from:

http://www.ribgh.org/documents/resources/2012_Rate_Review_Process_Hospital_Contracting_Conditions_Standard_Form_of_ Consent_7-30-12_Final.pdf

[18] Voss R, Gardner R, Baier RR, Butterfield K, Lehrman S, Gravenstein S. The Care Transitions Intervention: translating from efficacy to effectiveness. Arch Int Med. 2011; 171(14): 1232-1237. PMid: 21788540.

http://dx.doi.org/10.1001/archinternmed.2011.278 